\title{
Drought without water
}

\section{Jean Palutikof}

Drought and Man: The 1972 Case History. Vol. 1 Nature Pleads Not Guilty; Vol.2

The Constant Catastrophe: Malnutrition, Famines and Drought.

Vol.1 by Rolando V. Garcia, Vol.2 by R.V. Garcia and Jose C. Escudero.

Pergamon: 1982. Vol.1 pp.300, £25, \$60; Vol.2 pp.204, £20, \$45.

ALTHOUGH related to events which took place over ten years ago, Drought and Man is of frightening relevance to the declining fortunes of the developing world. It is a study in exploitation: of poorer countries by rich ones and, within nations, of the poor classes of society by the rich. In particular, it deals with the processes by which these forms of exploitation render the poor increasingly vulnerable to the impact of drought.

Nineteen seventy-two was a year marked by the exceptionally widespread and severe occurrence of drought. In the Sahel it was the fifth consecutive year, and the water deficit was far greater than in any of the preceding years. Drought was also experienced in the USSR, Australia and India. Following a series of seminars, the International Federation of Institutes for Advanced Study and the Aspen Institute for Humanistic Studies commissioned a comprehensive study of the impact of these droughts. The findings will ultimately be presented in three volumes, of which two are currently available.

Presenting an analysis of an event a decade after it occurred, particularly one as well researched as the 1972 drought, creates certain problems. In particular, it would be all too easy to lapse into laborious repetition of existing hypotheses to explain variations in the nature and severity of the effects of drought. Garcia avoids this problem and indeed takes positive advantage of the historical perspective that the passage of time affords. He is able to take a much more global view, both geographically and thematically, than was possible for authors writing contemporary to the event. By subjecting the political and economic backgrounds of the drought to what is basically a Marxist interpretation, Garcia produces a convincing explanation of why certain societies suffered such devastating ill-effects when others escaped relatively unscathed.

Volume 1, Nature Pleads Not Guilty, opens with a review of the literature on the 1972 food crisis. The international grain shortages and escalating prices which began about then have commonly been blamed on the widespread occurrence of drought in that year. Garcia maintains that the situation arose not from any physical cause but because failing confidence in the dollar drove speculators into commodity trading, and because the US Government began to realign its agricultural policy.
There then follows an analysis of the causes of national differences in drought impact. By differentiating between those societies which are vulnerable to drought and those which are resilient, and tracing the historical circumstances of example nations through the colonial and postcolonial eras, Garcia demonstrates convincingly the importance of political and economic choice. The extent to which the role of climate is relegated to a secondary position is shown by the fact that the only detailed treatment of the topic is found in the last two chapters of Vol. 1. However, the essay on global climatic variability by Smagorinsky was well worth waiting for: a logical and clear exposition of a complex topic.

Volume 2, The Constant Catastrophe, takes as its theme malnutrition as a measure of vulnerability to drought. Dismissing official statistics as inaccurate, if not misleading, the authors investigate the real extent of malnutrition in a number of case-study examples. Countries with high endemic rates of malnutrition amongst the poorer classes are contrasted with China, where a real effort was made to spread the available resources across the whole of society.
The final chapters make some suggestions for action. At this point, however, the authors have worked themselves into something of a corner: stringent criticism of political and economic structures implies the need for radical, if not revolutionary, change. Clearly the authors did not feel in a position to make this statement, and thus the recommendations make a somewhat feeble anticlimax to what has been a fascinating story.

Potential buyers of Vol.2 should also note that it repeats, almost verbatim, large chunks of material from Vol.1. Only this latter volume fully merits the substantial outlay required for its purchase.

Drought and Man should be required reading for those working in the field of natural hazard impacts who approach the subject from the viewpoint of the earth sciences. Quite naturally, such a background imposes an interpretation of events which stresses, in some cases to the exclusion of all else, the role of the physical event itself. These volumes provide the economic and political context which may be lacking for those without formal training in these disciplines. Having said this, it is necessary to add that for any other audience these works provide a dangerously biased view. There is an almost total failure to recognize the importance of such physical factors as the size of the water deficit and its season-toseason persistency. In fact, the influence of climate in general is largely discounted. Haste the day when a truly balanced and interdisciplinary study of natural hazard impacts finally reaches the bookshops.

Jean Palutikof is in the Climatic Research Unit at the University of East Anglia. 